\title{
Commentary \\ The riddle of hyperlactatemia
}

\section{Guillermo Gutierrez and Jeffrey D Williams}

The George Washington University, Medical Faculty Associates, 2150 Pennsylvania Avenue, N.W., Suite 5-427, Washington, DC 20037, USA

Corresponding author: Guillermo Gutierrez, ggutierrez@mfa.gwu.edu

Published: 12 August 2009

Critical Care 2009, 13:176 (doi:10.1186/cc7982)

This article is online at http://ccforum.com/content/13/4/176

(c) 2009 BioMed Central Ltd

See related research by Khosravani et al., http://ccforum.com/content/13/3/R90

\begin{abstract}
A recent observational study in a large cohort of critically ill patients confirms the association between hyperlactatemia and mortality. The mechanisms regulating the rates of lactate production and clearance in critical illness remain poorly understood. During exercise, hyperlactatemia clearly results from an imbalance between oxygen delivery and energy requirements. In critically ill patients, the genesis of hyperlactatemia is significantly more complex. Possible mechanisms include regional hypoperfusion, an inflammation-induced upregulation of the glycolitic flux, alterations in lactate-clearing mechanisms, and increases in the work of breathing. Understanding how these complex processes interact to produce elevations in lactate continues to be an important area of research.
\end{abstract}

The lack of a reliable indicator to assess cellular hypoxia and monitor the effectiveness of therapeutic interventions remains a major challenge in critical care medicine. In a study published in the previous issue of Critical Care, Khosravani and colleagues [1] further illustrated the independent association between mortality and blood lactate levels. They noted an independent association between mortality and blood lactate levels of above $2.0 \mathrm{mmol} / \mathrm{L}$. Their study is important for several reasons. First, the authors cast a wide net by including all adult intensive care unit admissions ( $n=13,932$ ) occurring during a 3 -year period in a welldefined patient population of 1.2 million. Over 12,000 patients had at least one lactate determination during their first 24 hours. Of these, $36 \%$ had a lactate concentration of greater than $2.0 \mathrm{mmol} / \mathrm{L}$ (the authors' definition of hyperlactatemia) and another 4\% developed hyperlactatemia later. Khosravani and colleagues [1] showed that hyperlactatemia, whether present at the time of presentation or developed later, was associated with increased mortality in a concentration-dependent manner.

The work of Khosravani and colleagues [1] corroborates prior clinical studies showing that even mild hyperlactatemia por- tends a poor outcome in critically ill patients. These include the early observations of increased blood lactate during hemorrhagic shock [2], the classic work of Weil and Afifi in cardiopulmonary resuscitation [3], and more recent studies showing mortality rates of nearly $70 \%$ being independently associated with lactate levels of at least $3.5 \mathrm{mmol} / \mathrm{L}$ [4].

Given its retrospective nature, the study by Khosravani and colleagues is purely descriptive and sheds little light on the pathophysiology of hyperlactatemia. The relationship between lactic acidosis and shock was first noted in 1843 by Johann Scherer, a German physician-chemist [5]. Louis Pasteur later advanced the theory that lactate was a hypoxia-related noxious metabolite [6]. Over half a century passed before the discoveries of the glycolytic pathway and the tricarboxylic acid (TCA) cycle [7] provided the metabolic framework to associate increases in blood lactate with tissue hypoxia [8]. Hyperlactatemia, however, carries different connotations, depending on the individual's physiological condition. For example, one would not predict the immediate demise of the Olympic athlete Michael Phelps based on an elevated blood lactate measured after a swim meet! This allusion to athletic prowess is not flippant: much of our understanding of lactate production in humans derives from exercise physiology [9], a paradigm that may not be wholly applicable to critical illness.

The failure to increase survival by increasing systemic oxygen delivery [10] suggests that mechanisms other than tissue hypoperfusion are responsible for the hyperlactatemia of critical illness. Among other factors that influence lactate accumulation in non-hypoxic cellular environments are an inflammation-induced upregulation of the glycolitic flux, alterations in lactate-clearing mechanisms, and increases in the work of breathing.

The metabolisms of lactate and glucose in sepsis are tied to the cellular inflammatory response [11]. Fully oxygenated

HIF-1 = hypoxia-inducible factor $1 ; \mathrm{TCA}=$ tricarboxylic acid. 
tissues may increase lactate production due to an enhanced glycolytic rate. This is regulated by cellular transcription factors such as the hypoxia-inducible factor 1 (HIF-1), which transcribes hundreds of genes in a cell type-specific manner. HIF-1 promotes the formation of lactate from pyruvate by activating lactate dehydrogenase and inducing pyruvate dehydrogenase kinase 1 , an enzyme that drives pyruvate away from the TCA cycle.

Elevations in blood lactate concentration also may result from an imbalance between production and clearance rates [12]. The liver efficiently removes lactate from blood, converting the lactate to glycogen (Cori cycle) [13]. Other organs capable of removing lactate from blood, such as the kidneys, brain, and skeletal muscle, also may be adversely affected by critically illness [14].

Finally, one must account for the contribution of work-ofbreathing increases in the presence of pulmonary edema and metabolic acidosis. Severe hyperlactatemia relating to ventilatory effort has been reported in asthmatic patients during acute exacerbations [15]. In addition, pulmonary lactate release occurs in direct proportion to lung injury, perhaps produced by highly active inflammatory cells [16]. How sepsis and other critical illnesses affect lactate production and clearance is by no means clear, but the data provided by Khosravani and colleagues spur us to continue the undertaking that began a century and a half ago with Scherer and Pasteur.

\section{Competing interests}

The authors declare that they have no competing interests.

\section{Acknowledgments}

This work was supported in part by a research grant from The Richard B. and Lynne V. Cheney Cardiovascular Institute.

\section{References}

1. Khosravani H, Shahpori R, Stelfox HT, Kirkpatrick AW, Laupland KB: Occurrence and adverse effect on outcome of hyperlactatemia in the critically ill. Crit Care 2009, 13:R90.

2. Peretz DI, McGregor M, Dossetor JB: Lactic acidosis: a clinically significant aspect of shock. Can Med Assoc J 1964, 90:673675.

3. Weil MH, Afifi A: Experimental and clinical studies on lactate and pyruvate as indicators of the severity of acute circulatory failure (shock). Circulation 1970, 41:989-1001.

4. Bernardin G, Pradier C, Tiger F, Deloffre P, Mattei M: Blood pressure and arterial lactate level are early indicators of shortterm survival in human septic shock. Intensive Care Med 1996, 22:17-25.

5. Kompanje EJ, Jansen TC, van der Hoven B, Bakker J: The first demonstration of lactic acid in human blood in shock by Johann Joseph Scherer (1814-1869) in January 1843. Intensive Care Med 2007, 33:1967-71.

6. Pasteur L: Influence of oxygen on the development of yeast and on the alcoholic fermentation. Annals and Magazine of Natural History (3rd series) 1861, 7:343-344.

7. Krebs HA, Johnson WA: The role of citric acid in intermediary metabolism in animal tissue. Enzymologia 1937, 4:148-156.

8. Rashkin MC, Bosken C, Baughman RP: Oxygen delivery in critically ill patients. Relationship to blood lactate and survival. Chest 1985, 87:580-584.

9. di Prampero PE, Ferreti G: The energetics of anaerobic muscle metabolism: a reappraisal of older and recent concepts. Respiration Phys 1999, 118:103-115.

10. Gattinoni L, Brazzi L, Pelosi P, Latini R, Tognoni G, Pesenti A, Fumagalli R: A trial of goal-oriented hemodynamic therapy in critically ill patients. SvO2 Collaborative Group. N Engl J Med 1995, 333:1025-1032.

11. Kellum JA, Song M, Li J: Lactic and hydrochloric acids induce different patterns of inflammatory response in LPS-stimulated RAW 264.7 cells. Am J Physiol Regul Integr Comp Physio/ 2004 286:R686-R692.

12. Gutierrez G, Wulf ME: Lactic acidosis in sepsis: a commentary. Intensive Care Med 1996, 22:2-16.

13. Cori CF: The enzymatic conversion of glucose-6-phosphate to glycogen. J Biol Chem (Baltimore) 1941, 140:309-310.

14. Bellomo R, Kellum JA, Pinsky MR: Transvisceral lactate fluxes during early endotoxemia. Chest 1996, 110:198-204.

15. Rabbat $A$, Laaban JP, Boussairi $A$, Rochemaure J: Hyperlactemia during acute severe asthma. Intensive Care Med 1998, 24:304312.

16. Brown SD, Clark C, Gutierrez G: Pulmonary lactate release in patients with sepsis and the adult respiratory distress syndrome. J Crit Care 1996, 11:2-8. 